\begin{tabular}{l|l} 
u.s. Department of & Office of \\
Science
\end{tabular}

\title{
Eddy Correlation Flux Measurement System (ECOR) Instrument Handbook
}

DR Cook RC Sullivan

Updated January 2020 


\section{DISCLAIMER}

This report was prepared as an account of work sponsored by the U.S. Government. Neither the United States nor any agency thereof, nor any of their employees, makes any warranty, express or implied, or assumes any legal liability or responsibility for the accuracy, completeness, or usefulness of any information, apparatus, product, or process disclosed, or represents that its use would not infringe privately owned rights. Reference herein to any specific commercial product, process, or service by trade name, trademark, manufacturer, or otherwise, does not necessarily constitute or imply its endorsement, recommendation, or favoring by the U.S. Government or any agency thereof. The views and opinions of authors expressed herein do not necessarily state or reflect those of the U.S. Government or any agency thereof. 


\title{
Eddy Correlation Flux Measurement System (ECOR) Instrument Handbook
}

\author{
DR Cook* \\ RC Sullivan \\ Both at Argonne National Laboratory \\ *Retired
}

Updated January 2020

Work supported by the U.S. Department of Energy,

Office of Science, Office of Biological and Environmental Research 


\section{Acronyms and Abbreviations}

2D

3D

$\mathrm{AMF}$

ARM

CF

DAC

DOE

DQ

DQ Explorer

DQR

ECOR

EF

EFSCO

ENA

GMT

IMMS

IR

IRGA

MET

NSA

OSS

PAR

QC

RMS

SEBS

SGP

SMOS

SOS

TWP

WPL

two-dimensional

three-dimensional

ARM Mobile Facility

Atmospheric Radiation Measurement

Central Facility

digital-to-analog converter

U.S. Department of Energy

Data Quality

Data Quality Explorer

Data Quality Report

eddy correlation (flux measurement)

extended facility

EF Surface Conditions Observations

East North Atlantic

Greenwich Mean Time

Instrument Mentor Monthly Summaries

infrared

infrared gas analyzer

surface meteorological instrumentation

North Slope of Alaska

Operations Status System

photosynthetically active radiation

quality control

root mean square

surface energy balance system

Southern Great Plains

surface meteorological observation system

speed of sound

Tropical Western Pacific

Webb, Pearman, Leuning 


\section{Contents}

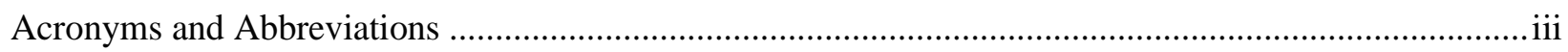

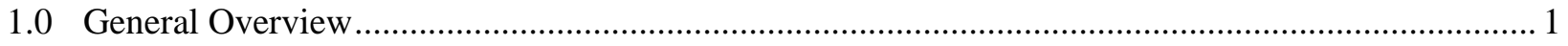

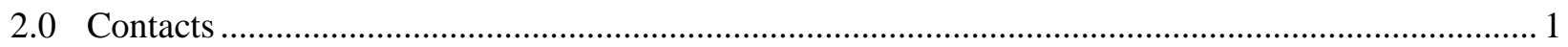

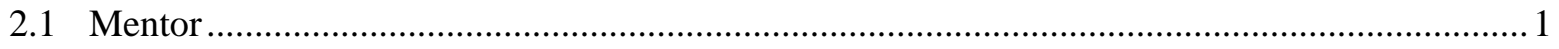

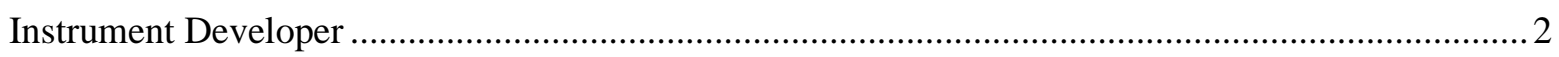

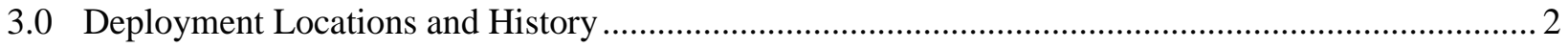

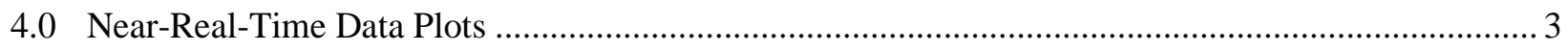

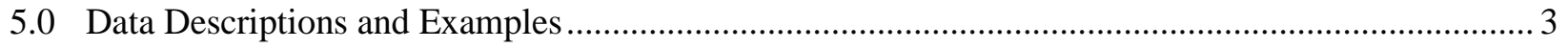

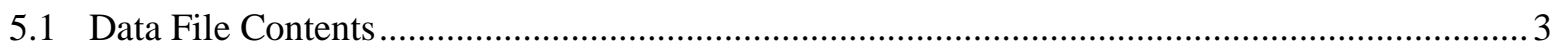

5.1.1 Primary Variables and Expected Uncertainty …........................................................... 3

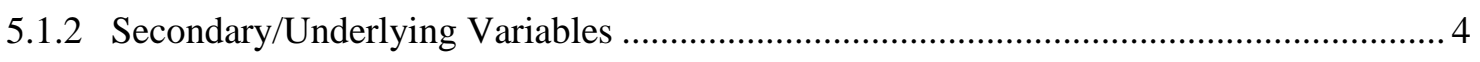

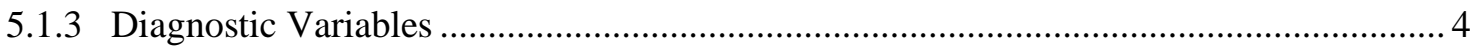

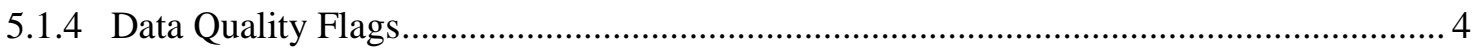

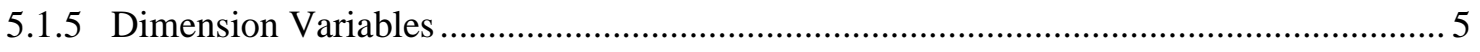

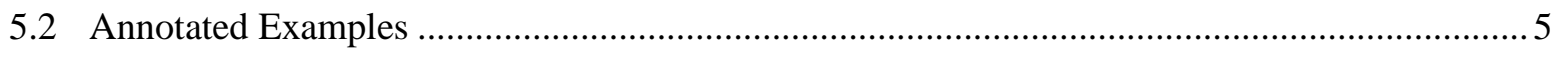

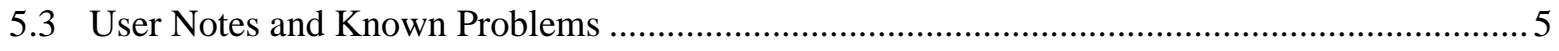

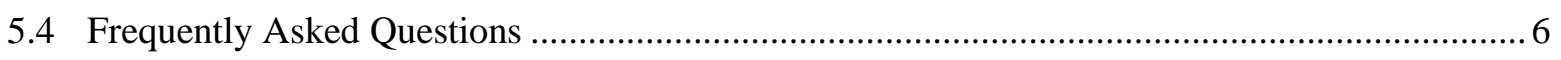

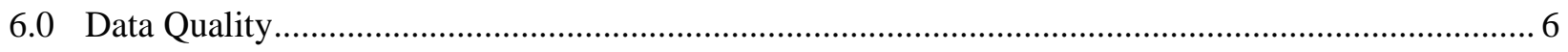

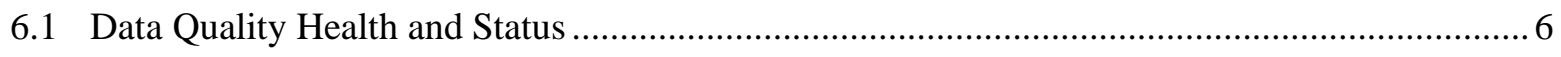

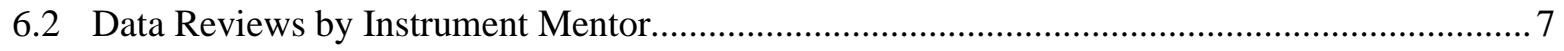

6.3 Data Assessments by Site Scientist/Data Quality Office ....................................................... 7

6.4 VAPS and Quality Measurement Experiments ....................................................................... 12

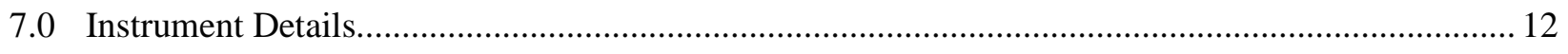

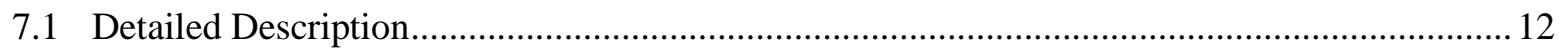

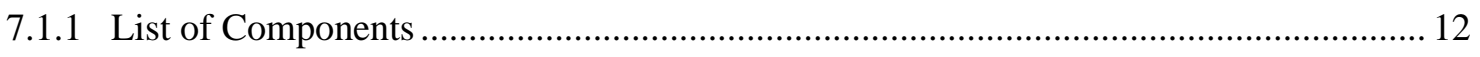

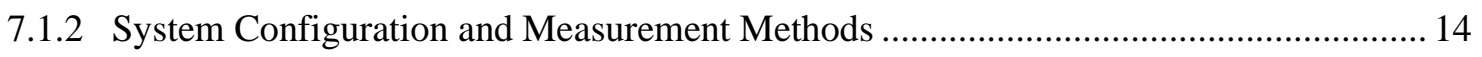

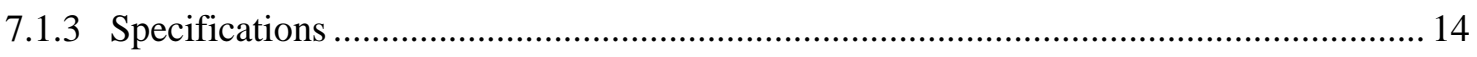

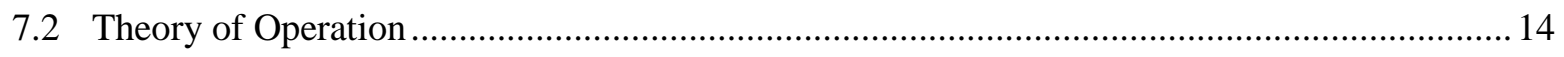

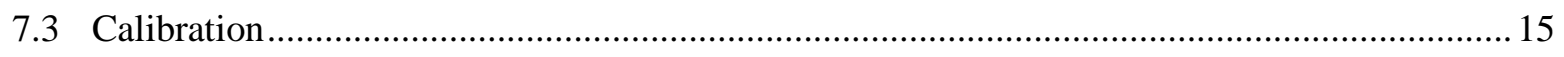

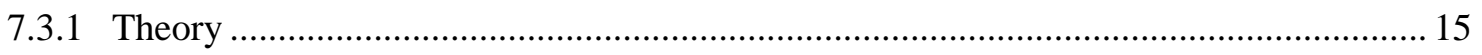

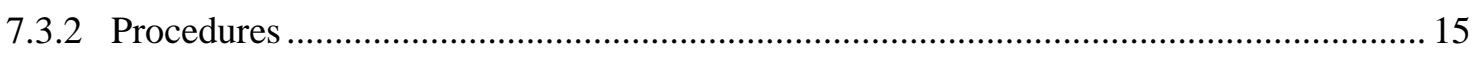

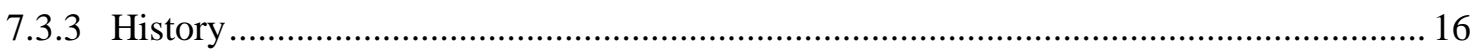

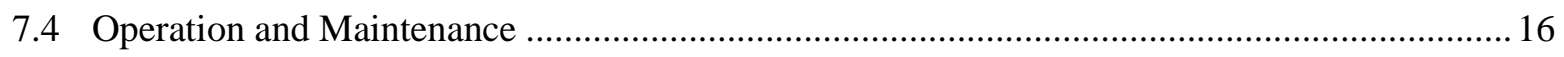

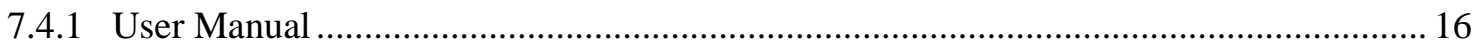

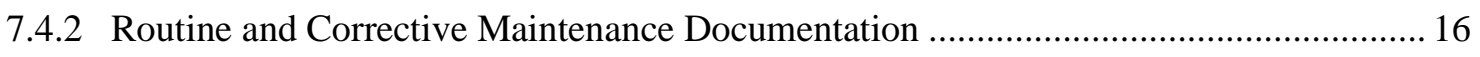

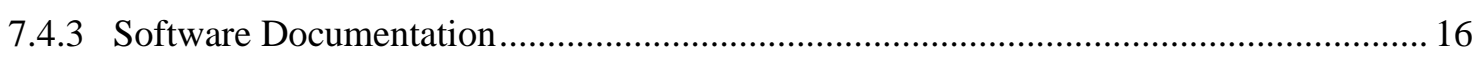

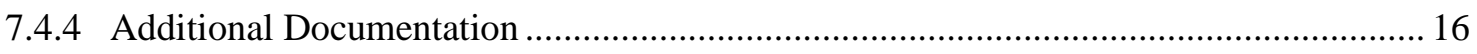

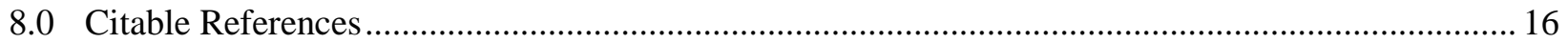




\section{Tables}

1 Deployment information of the ECOR flux measurement system................................................... 2

2 Calculated quantities for each 30 -minute interval.......................................................................... 3 


\subsection{General Overview}

The eddy correlation (ECOR) flux measurement system provides in situ, half-hour measurements of the surface turbulent fluxes of momentum, sensible heat, latent heat, and carbon dioxide $\left(\mathrm{CO}_{2}\right)$ and methane at the U.S. Department of Energy (DOE) Atmospheric Radiation Measurement (ARM) user facility's North Slope of Alaska central facility (NSA Barrow), and at the ARM Mobile Facility (AMF) deployment at Oliktok Point (OLI). The fluxes are obtained with the eddy covariance technique, which involves correlation of the vertical wind component with the horizontal wind component, the air temperature, the water vapor density, and the $\mathrm{CO}_{2}$ concentration. The instruments used are:

- a fast-response, three-dimensional (3D) wind sensor (sonic anemometer) to obtain the orthogonal wind components and the speed of sound (SOS) (used to derive the air temperature)

- an open-path infrared gas analyzer (IRGA) to obtain the water vapor density and the $\mathrm{CO}_{2}$ concentration, and

- an open-path infrared gas analyzer (IRGA) to obtain methane density and methane flux at NSA Barrow and at the AMF deployment at Oliktok Point.

The ECOR systems are deployed at the locations where other methods for surface flux measurements (e.g., energy balance Bowen ratio [EBBR] systems) are difficult to employ, primarily at the north edge of a field of crops.

A surface energy balance system (SEBS) has been installed collocated with each deployed ECOR system in SGP, NSA, Eastern North Atlantic (ENA), and each of three ARM Mobile Facilities. The SEBS consists of upwelling and downwelling solar and infrared radiometers within one net radiometer, a wetness sensor, and soil measurements. The SEBS measurements allow the comparison of ECOR sensible and latent heat fluxes with the energy balance determined from the SEBS and provide information on wetting of the sensors for data-quality purposes.

\subsection{Contacts}

\subsection{Mentor}

Ryan C. Sullivan

Environmental Science Division

Argonne National Laboratory, Bldg. 240

9700 S. Cass Avenue

Lemont, Illinois 60439-4843

Phone: 630.252.1270

rcsullivan@anl.gov 


\section{Instrument Developer}

\section{Sensor Vendors}

3D sonic anemometer, model Windmaster (SGP, ENA, AMF1) and WindMaster Pro (NSA, AMF2, AMF3): Gill Instruments, Limited, http://www.gill.co.uk (U.S. distributor: PP Systems, (978) 834-0505, support@ppsystems.com)

IRGA, $\mathrm{CO}_{2} / \mathrm{H}_{2} \mathrm{O}$ model LI-7500 and LI-7500DS (SGP only, after Oct. 2019): LI-COR, Inc., http://www.licor.com/env/

(LI-COR Environmental, (402) 467-3576, (800) 447-3576)

IRGA, $\mathrm{CH}_{4}$, model LI-7700 (NSA and OLI only): LI-COR, Inc., http://www.licor.com/env/products/gas analyzers/LI-7700/LI-7700.jsp

(LI-COR Environmental, (402) 467-3576, (800) 447-3576)

\subsection{Deployment Locations and History}

Table 1 shows the site locations of the ECOR flux measurement system.

Table 1. Deployment information of the ECOR flux measurement system.

\begin{tabular}{|c|c|c|c|}
\hline Facility & Location & Date Installed & Status \\
\hline SGP/EF1 & Larned, KS & 3/9/2004 & Removed 10/14/2009 \\
\hline SGP/EF3 & LeRoy, KS & 3/7/2004 & Removed 10/24/2009 \\
\hline SGP/EF5 & Halstead, KS & 9/9/2003 & Removed 11/02/2009 \\
\hline SGP/EF6 & Towanda, KS & $9 / 15 / 2003$ & Removed 10/18/2011 \\
\hline SGP/EF10 & Tyro, KS & $10 / 3 / 2003$ & Removed 08/31/2011 \\
\hline SGP/EF14 & Lamont, OK & 6/3/2003 & Operational \\
\hline SGP/EF16 & Vici, OK & $9 / 25 / 2003$ & Removed 06/08/2011 \\
\hline SGP/EF21 & Okmulgee, OK & $2 / 11 / 2004$ & Removed 05/02/2019 \\
\hline SGP/EF24 & Cyril, OK & $3 / 18 / 2004$ & Removed 11/14/2009 \\
\hline SGP/EF31 & Anthony, KS & $11 / 15 / 2011$ & Operational \\
\hline SGP/EF33 & Newkirk, OK & 08/15/2011 & Operational \\
\hline SGP/EF37 & Waukomis, OK & $11 / 29 / 2011$ & Operational \\
\hline SGP/EF38 & Omega, OK & $08 / 19 / 2011$ & Operational \\
\hline SGP/EF39 & Morrison, OK & $10 / 06 / 2015$ & Operational \\
\hline SGP/EF41 & Peckham, OK & $04 / 26 / 2016$ & Operational \\
\hline AMF1 & Various & $2 / 1 / 2005$ & Operational \\
\hline AMF2 & Various & $11 / 1 / 2010$ & Operational \\
\hline AMF3 & Oliktok, AK & $07 / 15 / 2014$ & Operational \\
\hline TWP/E30 & East ARM & $8 / 11 / 2010$ & Removed 01/10/2015 \\
\hline TWP/E31 & Beatrice Hill & $08 / 13 / 2010$ & Removed 01/03/2015 \\
\hline
\end{tabular}




\begin{tabular}{|c|c|c|c|}
\hline Facility & Location & Date Installed & Status \\
\hline TWP/E32 & Berrimah & $08 / 02 / 2010$ & Removed 01/10/2015 \\
\hline NSA/E1 & Barrow & $09 / 13 / 2011$ & Operational \\
\hline NSA/E2 & Point Barrow & $06 / 03 / 2012$ & Removed 12/06/2016 \\
\hline ENA & Azores, Portugal & $07 / 03 / 2014$ & Operational \\
\hline
\end{tabular}

\subsection{Near-Real-Time Data Plots}

Near-real-time data plots can be accessed via the ARM Data Quality Explorer (http://dq.arm.gov/dqexplorer/cgi-bin/main); choose "30ecor" ("ecorsf” for SGP after Oct. 2019) as "Datastream" in the corresponding scroll boxes.

\subsection{Data Descriptions and Examples}

\subsection{Data File Contents}

Currently, the ECOR systems produce 00- and b1-level data files. Initial processing takes place on the ECOR computer at the end of each half-hour measuring period. The data ingest process adds quality control (QC) flags and generates daily b1-level netCDF files, in keeping with ARM policy.

Both raw data (00 level) and b1 datastreams are routinely shipped to the ARM Data Center. Although b1 data are available through the standard Data Center interface, the raw data ( 00 level) are available only by request to the ARM Data Center (armarchive@ornl.gov).

\subsubsection{Primary Variables and Expected Uncertainty}

The ECOR system makes direct measurements at a rate of $10 \mathrm{~Hz}$ of the following parameters:

- Three wind components: $u, v$, and $w\left(\mathrm{~m} \mathrm{~s}^{-1}\right)$

- SOS, s ( $\left.\mathrm{m} \mathrm{s}^{-1}\right)$, which is used to derive atmospheric temperature, ta $\left({ }^{\circ} \mathrm{K}\right)$

- Water vapor density, q $\left(\mathrm{mmol} \mathrm{m}^{-3}\right)$

- $\mathrm{CO}_{2}$ concentration, c $\left(\mathrm{mmol} \mathrm{m}^{-3}\right)$

- Atmospheric pressure, pa $(\mathrm{kPa})$.

Table 2. Calculated quantities for each 30-minute interval.

\begin{tabular}{|l|l|l|}
\hline \multicolumn{1}{|c|}{ Variable } & \multicolumn{1}{c|}{ Name in netCDF file } & \multicolumn{1}{c|}{ Unit } \\
\hline Sensible heat flux, $H$ & $\mathrm{H}$ & $\mathrm{W} \mathrm{m}^{-2}$ \\
\hline Latent heat flux, $L_{v} E$ & $\mathrm{lv} \_\mathrm{e}$ & $\mathrm{W} \mathrm{m}^{-2}$ \\
\hline Momentum flux (dynamic), $M$ & $\mathrm{~K}$ & $\mathrm{~kg} \mathrm{~m}^{-1} \mathrm{~s}^{-2}$ \\
\hline Friction velocity, $u_{*}$ & Ustar & $\mathrm{m} \mathrm{s}^{-1}$ \\
\hline $\mathrm{CO}_{2}$ flux, $F_{C O 2}$ & Fc & $\mu \mathrm{mol} \mathrm{m}^{-2} \mathrm{~s}^{-1}$ \\
\hline Mean wind speed (vector averaged), $V$ & windpipe & $\mathrm{m} \mathrm{s}^{-1}$ \\
\hline
\end{tabular}




\begin{tabular}{|l|l|l|}
\hline \multicolumn{1}{|c|}{ Variable } & \multicolumn{1}{c|}{ Name in netCDF file } & \multicolumn{1}{c|}{ Unit } \\
\hline Mean wind direction, $D$ & wind_dir & $\mathrm{deg}$ \\
\hline Mean atmospheric temperature, $T_{a}$ & mean_t & ${ }^{\circ} \mathrm{K}$ \\
\hline Mean water vapor density, $Q$ & mean_q & $\mathrm{mmol} \mathrm{m}^{-3}$ \\
\hline Mean $\mathrm{CO}_{2}$ concentration, $C$ & mean_c & $\mathrm{mmol} \mathrm{m}^{-3}$ \\
\hline Mean atmospheric pressure, $P_{a}$ & atm_pres & $\mathrm{kPa}$ \\
\hline
\end{tabular}

Expected uncertainties of the fluxes, due to measurement accuracies of primary variables, are within the following limits: $\delta H=6 \%, \delta L_{v} E=5 \%, \delta M=5 \%, \delta F_{C O 2}=4 \%$.

\subsubsection{Definition of Uncertainty}

This section is not applicable to this instrument.

\subsubsection{Secondary/Underlying Variables}

The b1-level data file contains all statistics that were used for estimating fluxes and a number of additional variables to support a variety of advanced QC procedures.

Calculated statistics include mean, variance, covariance, skewness, and kurtosis of each of the primary measured values: u, v, w, Ta, q, and c. A two-axis coordinates rotation procedure is applied to find vertical turbulent fluxes; all relevant rotated statistics (rotation angles, means, variances, and covariances) are included in the data file. The file also contains standard deviations of wind direction and wind elevation angle. Several air parameters needed to obtain fluxes in conventional "density"-based units (moist air density, specific heat capacity, etc.) are also in the data file.

\subsubsection{Diagnostic Variables}

Several types of diagnostics variables are kept in the b1 file:

1. Data processing: Number of valid samples for each primary variable, number, and means of detected and removed outliers, number of invalid or out-of-range samples.

2. Sensor status: Serial number of the sensor, number of samples with invalid sonic status flag, number of samples with invalid IRGA status flag ("hardware problem” and "blocked optical path" given separately), IRGA calibration factors used to convert voltages into physical units, and the time lag value used to synchronize sonic and IRGA datastreams. The SGP systems with LI-7000DS also include status indicators for the IRGA chopper motor, optical filter wheel, and detector.

3. Environmental: Average voltage of IRGA cooler, average temperature inside the IRGA electronics enclosure. The SGP systems in LI-7000DS output $\mathrm{CO}_{2}$ signal strength, which can be useful in indicating when precipitation, fog, dew, or frost is obstructing the optical path.

\subsubsection{Data Quality Flags}

The b1 data file contains basic data quality flags for most important variables; the flags indicate the variable status (bit values), as follows: 
- $0 \mathrm{x} 0=$ value is within the specified range.

- $0 x 1$ = value is equal to "missing_value."

- $0 \times 2$ = value is less than "valid_min."

- 0x4 = value is greater than "valid_max."

- $0 x 8$ = value failed the "valid_delta” check.

The upgraded ECOR systems installed at SGP in October 2019 also include quality flags for tests of steady state and well-developed turbulence assumptions, and thresholds for spike count/removal, amplitude resolution, drop-outs, absolute limits, and skewness/kurtosis.

\subsubsection{Dimension Variables}

The global attributes section of the netCDF data file contains geographic coordinates (location) of the ECOR system and the altitude of the ground where the instrument is deployed; the "sensor location" parameter refers to the height of the instrument above the ground. The time variables denote the beginning of the 30-minute measuring period (end of 30-minute measuring period for ecorsf).

The sign convention for primary (measured) variables and estimated quantities is positive for upward vertical wind component and upward atmospheric flux.

The standard ARM site arrangement has the sonic sensor "North" mark pointing along the boom to the tower; the boom is usually pointing due south; the $u$ wind component is north-south with positive toward the north; and the $v$ wind component is east-west with positive toward the west. NOTE: No correction is made to convert the $u$ or $v$ component into the meteorological "north" or "east" wind component when the tower boom is not aligned to the south; the $u$ wind component is "along boom," the $v$ wind component is "cross boom."

\subsection{Annotated Examples}

Not available at this time.

\subsection{User Notes and Known Problems}

Measurement inadequacies are known to exist in the eddy covariance measurement technique. Instrument limitations are the source of most of the measurement problems (Cook et al. 2006, Twine et al. 2000). The sources are listed below:

1. Real temperature values derived from sonic SOS measurements by the WindMaster Pro are significantly overestimated at low temperatures and underestimated at high temperatures. Calibration of nine sonic anemometers in a temperature-and-humidity-controlled environment showed that each sensor temperature response was biased and had a "slope" that differed significantly from 1:1, ranging from 0.71 to 0.87 . Bias has no influence on sensible heat flux estimates, but these "slopes" translate directly into a significant sensible heat flux underestimation (this then affects corrections to the latent heat flux and $\mathrm{CO}_{2}$ flux in the ECOR value-added products (VAPs) that are based on sensible heat flux). This problem became apparent during final tryouts of the system, when it was too 
late to change to another sonic model or vendor. A linear correction procedure was implemented to account for the identified sensor deficiency; a more detailed discussion is in Pekour (2004).

2. The ECOR technique has a measurement uncertainty of about $10 \%$ just due to calibration issues, biases, vertical alignment, etc. Part of this uncertainty is sometimes reduced through judicious processing of the data, which is done every half hour, mostly in the ECOR VAP post-processing (vertical alignment and sonic SOS temperature corrections are included in the original ECOR datastream data).

3. Flux shortfalls of $10 \%$ to $25 \%$ are often seen in ECOR results (35\% shortfalls are less common, but can occur), even after post-processing, with the smallest shortfalls for bare soil and short vegetation and the largest shortfalls for tall vegetation like forests, corn, etc. Some conditions that can cause the shortfall include:

- Canopy energy storage: There is storage of energy in the vegetation canopy and litter that is not accounted for by the eddy covariance technique or in the radiation/soil heat flux measurements (such as measured by the EBBR) that determine the energy balance against which the ECOR measurements are typically compared.

- Sonic anemometer frequency measurement limitation: The sonic anemometer is physically incapable of properly measuring the lowest-frequency components of flux. The size of the sensing volume of the sonic limits its ability to capture larger atmospheric motions that make up the low-frequency component (atmospheric wave motions, horizontal and vertical advection caused by topography, dissimilar surfaces downwind of the main fetch, and changes in air mass).

- Non-steady atmospheric conditions: Rapid changes in wind direction, atmospheric stability, temperature, pressure, water vapor content, and $\mathrm{CO}_{2}$ content over a period of seconds to several minutes can be too rapid or sustaining for the covariances to be properly calculated.

\subsection{Frequently Asked Questions}

Where do I get more information about ECOR systems?

Contact the instrument mentor at rcsullivan@anl.gov.

\subsection{Data Quality}

\subsection{Data Quality Health and Status}

The following links go to current data quality health and status results.

- Data Quality Explorer (http://dq.arm.gov/dq-explorer/cgi-bin/main)

- NCVweb for interactive data plotting (https://plot.dmf.arm.gov/ncvweb/ncvweb.cgi)

The tables and graphs shown contain the techniques used by ARM's data quality analysts, instrument mentors, and site scientists to monitor and diagnose data quality. 


\subsection{Data Reviews by Instrument Mentor}

- Visual QC frequency: Daily to weekly

- QC delay: Typically 1-3 days

- QC type: Instrument mentor routinely views graphic displays that include plots (day courses) of all calculated quantities and comparison plots (time series or scatter plots) of relevant parameters with data from adjacent ECOR/EBBR systems (SGP CF and EF39 sites only) and collocated SEBS (surface energy balance system) and MET (surface meteorological instrumentation) systems (not at EF10 and EF16) (Cook et al. 2006).

- Monthly reviews of the ECOR data were prepared by the mentor and submitted to the Instrument Mentor Monthly Summary (IMMS) report database. These reports ended in late 2014. Beginning in FY2006, Data Quality Reports (DQRs) are not written for missing data or for situations when QC flags clearly show that the data are incorrect (this is true for most of the conditions listed below). DQRs are written for periods when data are incorrect, when the situation is not represented by QC flags in the data, and when it is not obvious that the data should have been flagged as incorrect.

\subsection{Data Assessments by Site Scientist/Data Quality Office}

The following guidance has been provided by the ECOR mentor for use by the Data Quality Office in preparing their weekly assessment report for the ECOR systems.

ECOR Data Quality Guidance

David R. Cook

16 December 2006

Introduction: The best way to tell someone what to look for in assessing the ECOR data is to describe conditions that reflect correct and incorrect data. For the most part, the QC checks provide adequate guidance. However, there are conditions for which the QC flags do not provide the needed guidance to be able to interpret the correctness of the data. Therefore, please use the information below as further guidance.

The fc and rho limits were changed in the ingest in late October 2005; therefore, fewer red QC flags should appear for those now.

Primary measurements: fc ( $\mathrm{CO}_{2}$ flux), lv_e (latent heat flux), h (sensible heat flux), $\mathrm{k}$ (momentum flux), ustar (friction velocity); all of these are calculated quantities. The QC limits set in the ingest are appropriate for the measurements (primary and otherwise), although sometimes legitimate values fall outside the QC limits.

Nuisance QC flags: The k and ustar flags are frequently tripped, especially at the E21 Okmulgee forested site. However, it is normally only when the minimum flag is tripped that there is concern about data quality; values below the minimum usually indicate low wind speed conditions $(<1 \mathrm{~m} / \mathrm{s})$ that do not produce accurate flux (fc, lv_e, h, k) measurements. 
Comparison of data at different ECOR sites: The measurements can generally be favorably compared with those at adjacent sites, keeping in mind that climate conditions from one side of the SGP site to another can differ sharply. However, comparisons cannot be made between the E14 (wheat, corn, stubble, bare soil) or E21 (forest) and the other ECORs, which make measurements over grass, because the surface vegetation types are different; such comparisons are likely to show significant differences.

Comparison of data with the EBBR: The only collocated ECOR (E14) and EBBR (E13) are at the SGP Central Facility (CF) and at E39. Caution must be used in comparing the two CF systems because they usually see different vegetation surfaces (Cook et al. 2006). The best comparison can be made for straight north or northwest wind directions, when both systems view the same grass surface. For other directions, the two systems are viewing different vegetation surfaces and the fluxes from the two will probably not be similar, unless perhaps, the ground is snow covered. Except for the E14 and E21 sites, sensible and latent heat flux, and wind speed and direction measurements can be compared for adjacent ECOR and EBBR systems (which all view grassland), again remembering that there are likely to be climatologically driven differences. No other measurements can be reliably compared, mostly because the ECOR LI-7500 and sonic anemometer are not meant to produce accurate measurements of anything else that both systems measure.

Comparison of data with MET systems: Met systems are collocated with ECOR systems at most sites (exceptions are SGP E10 and E16). There are no measurements of the two systems that can be directly compared. Wind speed and direction for the two systems are at different heights (surface meteorological observation system [SMOS] $10 \mathrm{~m}$, ECOR $3 \mathrm{~m}$ ), so it is expected that the SMOS wind speed will be greater than the ECOR wind speed. Wind direction may be similar but somewhat different if a frontal passage or strong advection is taking place. The ECOR temperatures (sonic and IRGA) and pressure (IRGA) are only approximate and are not meant to provide the same accuracy as the SMOS absolute measurements; therefore, they can be expected to be considerably different under warm weather conditions, especially.

Comparisons with SEBS systems: SEBS systems are co-located with all ECOR systems. The surface energy balance measurement can be compared with the sum of sensible and latent heat fluxes to indicate any underestimation of the sum of the fluxes. The wetness measurement indicates precipitation/dew/frost conditions that would cause ECOR latent heat flux and $\mathrm{CO}_{2}$ flux measurements to be suspect or incorrect.

Common conditions reflecting correct or incorrect data: The ECOR data are only useful for particular wind directions at each extended facility (EF). Please use the following resources to help in interpreting the ECOR data from the "new" systems that were installed in 2004:

1. QC flags in the ECOR data.

2. Data quality reports (DQRs) at https://adc.arm.gov/dqrws/.

3. The information below on wind direction dependencies and conditions that commonly cause incorrect data.

Wind direction dependencies (numbers are wind direction in degrees): the vegetation surfaces and corresponding wind directions over which the fluxes have been measured are listed; wind directions that are not listed are directions for which the fetch is insufficient, and therefore, for which the ECOR flux data are suspect. Appropriate fetch was determined from a 1/70 measurement height to fetch ratio, resulting in a required minimum fetch of $210 \mathrm{~m}$. Changes in surface vegetation type and state can occur 
with time (refer to the EFSCO available at https://www.ops.sgp.arm.gov/ under "Extended Facility Vegetation Observations” and selecting “Sign In as Guest”):

\section{AMF1 and AMF2:}

Point Reyes, California (PYE): For some wind directions, the horizontal fetch was not representative of the field in which the AMF was located. Therefore, for the wind direction ranges 66-92 (buildings and trees) degrees, the fluxes are affected by insufficient fetch and surfaces, buildings, or vegetation that are not similar to the local field conditions.

Niamey, Niger (NIM): For some wind directions, the horizontal fetch was not representative of the field in which the AMF was located. Therefore, for the wind direction ranges 90-170 (buildings) and 220-280 (trees) degrees, the fluxes are affected by insufficient fetch and surfaces, buildings, or vegetation that are not similar to the local field conditions.

Hesselbach, Germany (FKB): For some wind directions, the horizontal fetch was not representative of the field in which the AMF was located. Therefore, for the wind direction ranges 40-159 and 176-209 degrees, the fluxes are affected by insufficient fetch and surfaces, buildings, and vegetation that are not similar to the local field conditions.

Steamboat Springs, Colorado (STORMVEX, SBS): snow all directions

Shouxian, China (HFE): ungrazed grass all directions

Gracious Island, Azores, Portugal (GRW): Grass 100-260; grass and low shrubs 270-360 and 0-99

Cape Cod (TCAP, PVC): Seashore grass and shrubs all directions; some saltwater sea influence 0-100

Brazil (MAO): ungrazed grass all directions

AWARE (Antarctic, AWR):

- West Antarctic Ice Shelf (WAIS): all directions snow/ice

- McMurdo: For some wind directions, the horizontal fetch was not representative of the tundra field in which the AMF2 was located. Therefore, the fluxes are affected by insufficient fetch and surfaces, buildings, and vegetation that are not similar to the tundra surface.

Sierras de Córdoba, Argentina (CACTI, COR): Limited fetch to the south (160-200) due to instrument containers, and to the southeast (100-120) due to meteorological tower.

Norway (COMBLE, ANX): Nordmela, Andøya (Main site): ocean 315-360, 0-80, 180-225. Bjørnøya (Bear Island): limited fetch 270-360 due to buildings.

AMF3/OLI: All directions tundra; all directions the fetch is limited 


\section{SGP:}

EF1: 0-53, 120-360 wheat or wheat stubble

EF3: 0-48 pasture; 132-260 soybeans, wheat

EF5: 80-154 sorghum or wheat; 155-260 wheat or wheat stubble

EF6: 0-90 grazed pasture; 91-360 alfalfa and brome grass

EF10: 0-90, 270-360 grazed; 91-269 grass

EF14: 129-265 wheat (2004), corn (2005), soybeans (2006); but normally wheat; 352-85 ungrazed grass

EF16: 134-269 pasture; 334-360 ungrazed grass

EF21: 0-360 mixed deciduous forest (note that for the direction of the tower, 0-30, the data may be suspect)

EF24: 80-280 wheat or wheat stubble

EF31: 100-200 corn/soybean; pasture 30-80

EF33: $100-300$ wheat; $40-80$ grass

EF37: 135-260 wheat; 280-310 pasture

EF38: 150-260 wheat

EF39: 100-260 wheat; 280-360 and 0-80 ungrazed grass

EF41: 100-260 wheat; $280-360$ and 0-80 ungrazed grass

ENA: All directions ungrazed grass; all directions the fetch is limited

NSA:

EF10: All directions tundra; 340 through 20 the fetch is limited

EF11: 350-360 and 0-100 saltwater sea; All other directions beach gravel

TWP:

EF30: $145-360$ and 0-100 saltwater sea

EF31: All directions grass/wetland

EF32: All directions ungrazed grass 
Some conditions that commonly cause the ECOR primary measurements to be incorrect or missing, plus some advice for interpreting the data are as follows:

- Periods of precipitation, fog, and dew (frost) often cause incorrect water vapor and $\mathrm{CO}_{2}$ measurements. This is caused by water lying on the lower window of the LI-7500 $\mathrm{CO}_{2} / \mathrm{H}_{2} \mathrm{O}$ sensor, thereby obstructing the passage of the sensing infrared (IR) radiation (very light precipitation may have little or no effect). The $\mathrm{CO}_{2}$ portion of the instrument is more sensitive to this condition, so it is not unusual for latent heat flux to be correct, even though the $\mathrm{CO}_{2}$ flux is not. I do not write DQRs or indicate time periods in the monthly report for this wetting condition. The data user should look at the SEBS wetness measurement (beginning in August 2011 at TWP ECOR/SEBS sites, mid-October at SGP E14 and E21 sites, and thereafter at other ARM ECOR/SEBS sites), collocated or nearby MET/SMOS rain gauges, or the DQ HandS ECOR plots to determine times of precipitation. You can assume that off-scale or spiked readings in the nighttime hours before dawn are normally caused by dew or frost on the $\mathrm{CO}_{2} / \mathrm{H}_{2} \mathrm{O}$ sensor.

- Large spikes (positive and negative) in $\mathrm{CO}_{2}$ flux can occur when the flux is essentially zero (see E16, 08/16/05, 0800-0930 GMT).

- Friction velocity (ustar) and momentum flux (k) are often flagged during light wind conditions. This is normal, because these measurements, as well as the fluxes of sensible heat flux (h), latent heat flux (lv_e), and $\mathrm{CO}_{2}$ flux (fc) cannot be trusted because of the lack of ability of the sonic anemometer to make proper measurements during very low wind speeds (especially $<1 \mathrm{~m} / \mathrm{s}$ ).

- Sudden shifts in wind direction are not handled well by the ECOR coordinate transform routine, often resulting in a spike in the fluxes for a half-hour measurement period.

- Momentum flux and friction velocity have opposite signs and mirror each other, because friction velocity is computed from momentum flux; in the DQ HandS plots they are plotted to scales with opposite sign orientations, so they trend together.

- ECOR time stamps are for the beginning of the half hour (ECORSF timestamps are for the end of the half hour), whereas those for the SMOS and EBBR are for the end of the half hour. Therefore, when comparing data for these systems (such as on DQ HandS plots), the ECOR measurements show a half hour earlier than the commensurate measurements for the SMOS and EBBR.

- Plots of water vapor flux (lv_e) and $\mathrm{CO}_{2}$ flux (fc) normally mirror each other: in the DQ HandS plots they are plotted to scales with opposite sign orientations, so they tend to trend together.

- During rare occasions, the QC flag for elevation (angle of attack of the wind) is exceeded, usually on the positive side. The QC flag limits for elevation are quite generous; this was done to try to accommodate the large angles that can occur at the forested Okmulgee site EF21. However, the angles at the Okmulgee site can often be much larger than the QC limits because of the very uneven height of trees in the mixed deciduous forest.

- Fluxes of $\mathrm{CO}_{2}$, sensible heat, and latent heat at E21 Okmulgee forest are often larger than at other sites, particularly the fluxes of water vapor and $\mathrm{CO}_{2}$; the latter will often be twice what it is at the other ECOR sites.

- The plots of data from the forest site at Okmulgee exhibit more noise than is seen at the other ECOR sites; this is expected and normal because the tree structure presents a much rougher and less homogeneous surface than exists for grassland or crops. 
- When the $\mathrm{LI}-7500 \mathrm{CO}_{2} / \mathrm{H}_{2} \mathrm{O}$ serial datastream is not available (pressure and temperature missing), default values are used in the calculation of the $\mathrm{CO}_{2}$ and latent heat fluxes; when default values are used, resulting errors in the fluxes are within the $+/-10 \%$ system error.

- Missing data periods occur at times; this is usually a site data system collection/communication problem; it can also occur if the ECOR data acquisition computer fails. Missing data are sometimes filled in later from manual or automatic re-collection of the data.

\subsection{VAPS and Quality Measurement Experiments}

The ECOR VAP (QCECOR) performs corrections of ECOR fluxes for WPL buoyancy effects (Webb et al. 1980), sensor separation and frequency attenuation effects, outlier removal, and filtering using the SEBS wetness measurement.

In October 2019, the ECOR systems at SGP where upgraded with newer instrument sensors and an on-board microprocessor, allowing processing and application of routine flux corrections to the primary datastream, ECORSF.

A separate VAP developed by David Billesbach of the University of Nebraska is run to process the full ECOR data set, with all corrections included, for the NSA Barrow and AMF3 Oliktok Point with the inclusion of methane fluxes.

\subsection{Instrument Details}

\subsection{Detailed Description}

\subsubsection{List of Components}

Ultrasonic anemometer: WindMaster Pro by Gill Instruments, Ltd. (http://www.gill.co.uk):

Full wind vector in the form of orthogonal wind components $u, v$, and $w$ Accuracy:

For $\mathrm{u}$ and $\mathrm{v}=1.5 \%$ root mean square (RMS) error for winds below $20 \mathrm{~ms}^{-1}, 3 \%$ otherwise

For $\mathrm{w}=3 \%$ of magnitude

SOS:

Range: 307 to $367 \mathrm{~ms}^{-1}$

Resolution: $0.01 \mathrm{~ms}^{-1}$

Accuracy: 3\% RMS error for winds $<20 \mathrm{~ms}^{-1}$, 6\% RMS error for winds 20 to $60 \mathrm{~ms}^{-1}$

Analog inputs:

Type: eight single-ended or four differential (software selectable)

Range: -5 to +5 VDC

Resolution: 14 bit

Accuracy: $0.05 \%$ of full scale (for temperature from +5 to $+35^{\circ} \mathrm{C}$ )

$0.1 \%$ of full scale (for -40 to $+5^{\circ} \mathrm{C},+35$ to $+60^{\circ} \mathrm{C}$ )

Open-path $\mathrm{CO}_{2} / \mathrm{H}_{2} \mathrm{O}$ IRGA: LI-7500 by LI-COR, Inc. (http://www.licor.com/env/):

Water vapor density 
Range: 0 to $2000 \mathrm{mmol} \mathrm{m}^{-3}$ (software selectable)

Accuracy: About 1\% (limited by calibration)

Precision: About $0.14 \mathrm{mmol} \mathrm{m}^{-3}$ (typical RMS noise).

$\mathrm{CO}_{2}$ concentration

Range: 8 to $32 \mathrm{mmol} \mathrm{m}^{-3}$ (software selectable)

Accuracy: About 1\% (limited by calibration)

Precision: About $4 \mu \mathrm{mol} \mathrm{m}{ }^{-3}$ (typical RMS noise).

Analog outputs

Type: Two-user selectable

Range: 0 to $5 \mathrm{~V}$ DC

Resolution: 16 bit

Update rate: $300 \mathrm{~Hz}$

Open-path $\mathrm{CO}_{2} / \mathrm{H}_{2} \mathrm{O}$ IRGA: LI-7500DS by LI-COR, Inc. (http://www.licor.com/env/):

Water vapor density

Range: Not specified

Accuracy: Within 1\%

Precision: About $0.0047 \mathrm{mmol} \mathrm{m}^{-3}$ (typical RMS noise).

$\mathrm{CO}_{2}$ concentration

Range: Not specified

Accuracy: Within 1\%

Precision: About 0.11 ppm (typical RMS noise).

Open-path $\mathbf{C H}_{4}$ IRGA: LI-7700 by LI-COR, Inc.

(http://www.licor.com/env/):

Methane concentration

Range: 0 to $25 \mathrm{ppm}$

Accuracy: About 1 (limited by concentration)

Resolution: $5 \mathrm{ppb}$

\section{LI-7550 Electronics Box:}

Analog output

Range: 0 to 5 V DC

Resolution: 16 bit

Update Rate: $40 \mathrm{~Hz}$

\section{Data acquisition computer:}

Single-board computer system using Linux operating system used until about 2012 (still used at NSA E11), thereafter by Virtual Machine.

Data collection and initial processing performed with ECOR software (written in C by R. Hart and M. Pekour at Argonne National Laboratory). 
For SGP after October 2019 (ECORSF datastream): Processing, quality flags, and corrections made on SmartFlux3 microprocessors (LI-COR, Inc.) running EddyPro software with default settings (“express mode”).

\subsubsection{System Configuration and Measurement Methods}

In a typical arrangement, the ECOR system is placed on the north side of a wheat field; sonic and IRGA sensor heads are mounted on a small tower at $3 \mathrm{~m}$ above ground level, at the end of a horizontal boom pointing south. The computer and communication devices are installed in an enclosure with basic temperature control (ventilation or heating). One exception to the usual arrangement is the Okmulgee site (EF21), where the ECOR system is installed on a tall tower (15 $\mathrm{m}$ above ground, about $3 \mathrm{~m}$ above the canopy) in a hardwood forest.

The IRGA provides fast-response measurements of water vapor density and $\mathrm{CO}_{2}$ concentration in digital and analog form; the sonic anemometer provides three wind components and the SOS data in digital form (retrieved via serial link) at a rate of $10 \mathrm{~Hz}$ and performs synchronous digitization of the IRGA analog outputs. The digital datastream from the IRGA is also recorded by the data acquisition computer; it is used to extract IRGA diagnostics values and as a second copy of the water vapor density and $\mathrm{CO}_{2}$ concentration data.

The raw datastream is recorded into raw data files by 30-min portions and is processed every half hour by the ECOR computer or SmartFlux microprocessor. The raw and processed data files are transferred to the SGP Central Facility for ingest (conversion into the netCDF format and incorporation of QC flags) and shipment to the ARM Data Center.

\subsubsection{Specifications}

This section is not applicable to this instrument.

\subsection{Theory of Operation}

The WindMaster Pro sonic anemometer uses three pairs of orthogonally oriented, ultrasonic transmitter/receiver transducers to measure the transit time of sound signals traveling between the transducer pairs in both directions. Pairs of measurements made along each axis, 30 times per second, are averaged appropriately to provide a $10-\mathrm{Hz}$ datastream. The wind speed along each axis is determined from the difference in transit times. The SOS is determined from the average transit time along all three axes. The air temperature can be derived from the SOS with a well-known correction for the humidity effects.

The IRGA measures water vapor density and $\mathrm{CO}_{2}$ density by detecting the absorption of IR radiation by water vapor or $\mathrm{CO}_{2}$ in the light path. Two IR wavelength bands are used, centered on strong water vapor or $\mathrm{CO}_{2}$ absorption lines. The sensor provides digital (serial RS232) and analog (two 16-bit, digital-to-analog converter [DAC]) outputs. Details of the IRGA principles, design, and performance can be obtained from LI-COR Environmental: http://www.licor.com/env/ . 
The sonic anemometer samples the gas analyzer analog outputs 10 times per second, synchronously with wind measurements, and combines all the data into a single serial datastream.

The data acquisition computer continuously records serial datastreams from both sensors and stores them into 30-minute files. Half-hourly flux data processing is accomplished on the same computer, independently of the data acquisition process. Half-hour-averaged ambient air temperature, water vapor pressure, and barometric pressure derived from the sonic anemometer and the IRGA raw data are used in the calculations of moist air density, specific heat of dry and moist air at constant pressure, and heat of vaporization of water necessary for presentation of the fluxes in "density-based” units.

Data analysis includes a de-spiking procedure, basic QC of every data point (sensor status, minimum/maximum check), time delay for the sonic data to account for the internal delay in the IRGA, conversion of the SOS into air temperature, and computation of statistics (mean, variance, covariance, skewness, kurtosis, etc.). Two-dimensional (2D) coordinate rotations are applied to the variances and covariances to achieve zero mean vertical wind speed.

Momentum flux is determined from the correlation between horizontal and vertical wind components in "rotated" coordinates. Similarly, the vertical fluxes of sensible heat, latent heat, and $\mathrm{CO}_{2}$ are determined directly from the correlation between the "rotated" vertical velocity and temperature, water vapor density, and $\mathrm{CO}_{2}$ concentration, respectively.

In general, the fluxes calculated as described represent vertical fluxes from a variable area (a footprint) of the surface upwind of the instrument. The size of this area usually varies from 10 to 100 times the height of the sensors above the surface. The footprint depends on surface properties (roughness, displacement height, etc.), atmospheric state and stability, and turbulent intensity within the atmospheric surface layer.

See Citable References for further discussions.

\subsection{Calibration}

\subsubsection{Theory}

Ideally, the sonic anemometer does not require calibration for either wind or temperature measurements, although the WindMaster Pro SOS channel needs to be calibrated to achieve accurate sensible heat measurement (see Pekour 2004 for more detailed discussion). The IRGA sensors need to be calibrated periodically. The IRGA is calibrated by passing gas of known concentration through a calibration tube installed in the sensor head, so that the tube surrounds the light path over which IR absorption is measured. The zero (offset) is typically calibrated by using "zero" gas or dry nitrogen from a gas cylinder. The gains of the $\mathrm{CO}_{2}$ and $\mathrm{H}_{2} \mathrm{O}$ channels are calibrated by using a cylinder with a known concentration of $\mathrm{CO}_{2}$ and flow from a water vapor generator (e.g., LI-COR, Inc. LI-610 Dew Point Generator).

\subsubsection{Procedures}

A chemical replacement and calibration procedure was developed and implemented for the ECOR LI- $7500 \mathrm{CO}_{2} / \mathrm{H}_{2} 0$ IRGA sensors. 


\subsubsection{History}

Calibration information is stored in the Operations Status System (OSS) and is available to instrument mentors. Please contact the instrument mentor for more information.

\subsection{Operation and Maintenance}

\subsubsection{User Manual}

No single comprehensive user manual for the ECOR system is available for general use; rather, vendor-supplied documentation on sensors and a collection of procedures prepared by mentors are provided for internal use by Site Operations.

\subsubsection{Routine and Corrective Maintenance Documentation}

The ECOR Preventive Maintenance procedures and reports are stored in the OSS. Please contact the instrument mentor for more information.

\subsubsection{Software Documentation}

Contact the instrument mentor (rcsullivan@anl.gov) for software documentation.

\subsubsection{Additional Documentation}

This section is not applicable to this instrument.

\subsection{Citable References}

Cook, DR, ML Fischer, and DJ Holdridge. 2006. "Comparison of ECOR, EBBR, and CO2FLX System Fluxes.” Abstract (from poster), Sixteenth ARM Science Team Meeting, Albuquerque, New Mexico.

Kaimal, JC, and JJ Finnigan. 1994. Atmospheric Boundary Layer Flows: Their Structure and Measurement. Oxford University Press, New York.

Massman, WJ and X Lee. 2002. "Eddy covariance flux corrections and uncertainties in long-term Studies of carbon and energy exchanges.” Agricultural and Forest Meteorology 113(1-4):121-144, https://www.sciencedirect.com/science/article/pii/S0168192302001053

Moore, CJ. 1986. "Frequency response corrections for eddy correlation systems.” Boundary-Layer Meteorology 37(1-2):17-35, https://link.springer.com/article/10.1007/BF00122754\#citeas

Pekour, MS. 2004. "Experiences with the Windmaster Pro Sonic Anemometer.” Proceeding of the $12^{\text {th }}$ International Symposium on Acoustic Remote Sensing, Clare College, Cambridge, United Kingdom, pp. 137-140.

Phillips, T, S Klein, H Ma, S Xie, I Williams, J Santanello, D Cook, and M Torn. 2018. “Using ARM Observations to Evaluate CAM5.1/CLM4 Simulations of Land-Atmosphere Coupling on the Southern Great Plains.” Poster, 2018 ARM/ASR PI Meeting, Vienna, Virginia. 
Sullivan, RC, and D Cook. 2018. “Comparison of EBBR and ECOR Flux Measurements at SGP E39.” Poster, 2018 ARM/ASR PI Meeting, Vienna, Virginia.

Sullivan, RC, and D Cook. 2019. "ECOR SmartFlux: Upgrading the ARM Eddy Correlation Flux Measurement Systems.” Poster, 2019 ARM/ASR PI Meeting, Rockville, Maryland.

Tang, S, S Xie, Y Zhang, Q Tang, M Zhang, and D Cook. 2018. “Uncertainty of Surface Turbulent Flux Measurements and It's Impacts to the Derived Large-Scale Forcing at the ARM SGP Site.” Poster, 2018 ARM/ASR PI Meeting, Vienna, Virginia.

Twine, TE, WP Kustas, JM Norman, DR Cook, PR Houser, TP Meyers, JH Prueger, PJ Starks, and ML Wesely. 2000. "Correcting eddy-covariance flux underestimates over a grassland.” Journal of Agricultural and Forest Meteorology 103(3):279-300, https://www.sciencedirect.com/science/article/pii/S0168192300001234

Webb, EK, GI Pearman, and R Leuning. 1980. "Correction of flux measurements for density effects due to heat and water vapour transfer.” Quarterly Journal of the Royal Meteorology Society 106(44): 85-100, https://rmets.onlinelibrary.wiley.com/doi/abs/10.1002/qj.49710644707

Wilczak, JM, SP Oncley, and SA Stage. 2001. "Sonic Anemometer Tilt Correction Algorithms.” Boundary-Layer Meteorology 99(1):127-150, https://link.springer.com/article/10.1023/A:1018966204465\#citeas 


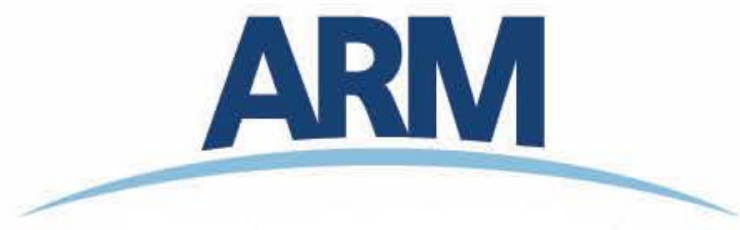

www.arm.gov
U.s. DEARTruEN ToF ENERGY

Office of Science 